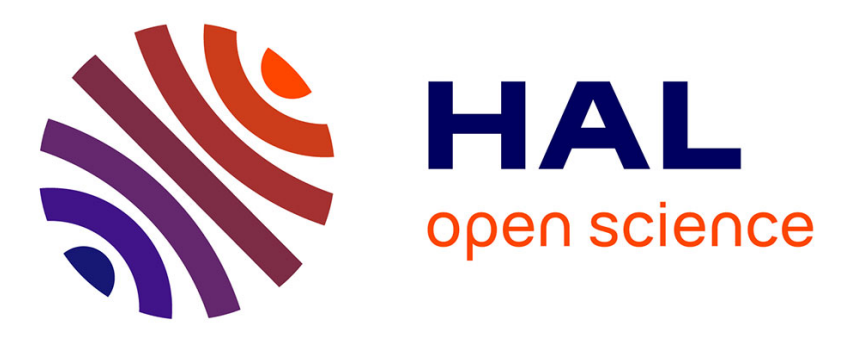

\title{
Characterization of the microstructure of dairy systems using automated image analysis
}

Juliana V.C. Silva, David Legland, Chantal Cauty, Irina Kolotuev, Juliane Floury

\section{- To cite this version: \\ Juliana V.C. Silva, David Legland, Chantal Cauty, Irina Kolotuev, Juliane Floury. Characterization of the microstructure of dairy systems using automated image analysis. Food Hydrocolloids, 2015, 44, pp.360-371. 10.1016/j.foodhyd.2014.09.028 . hal-01130408}

\section{HAL Id: hal-01130408 \\ https://hal-univ-rennes1.archives-ouvertes.fr/hal-01130408}

Submitted on 11 Mar 2015

HAL is a multi-disciplinary open access archive for the deposit and dissemination of scientific research documents, whether they are published or not. The documents may come from teaching and research institutions in France or abroad, or from public or private research centers.
L'archive ouverte pluridisciplinaire HAL, est destinée au dépôt et à la diffusion de documents scientifiques de niveau recherche, publiés ou non, émanant des établissements d'enseignement et de recherche français ou étrangers, des laboratoires publics ou privés. 


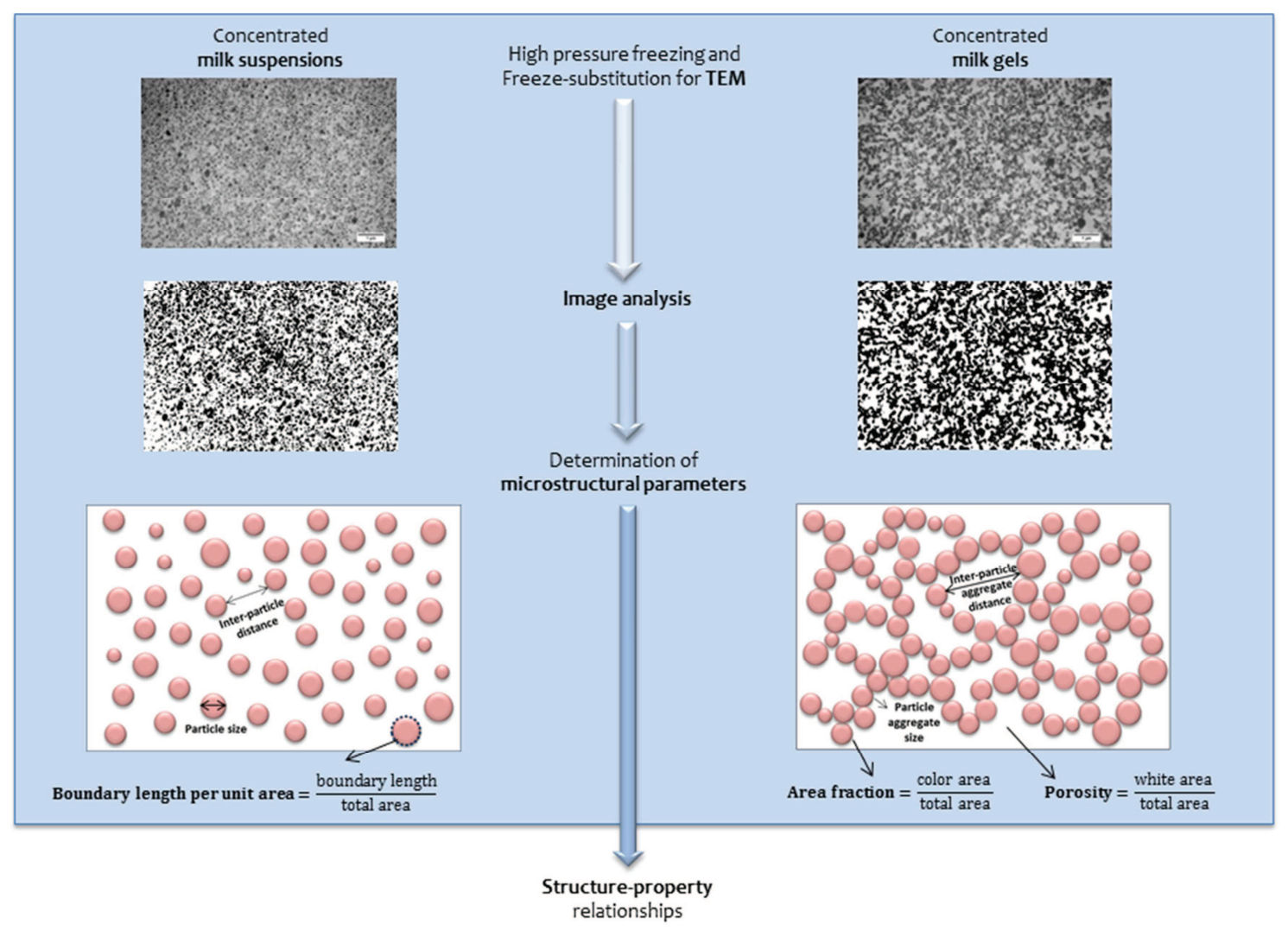


1 Characterization of the microstructure of dairy systems using automated image analysis

2

3 Juliana V. C. Silva ${ }^{\mathrm{a}}$, David Legland ${ }^{\mathrm{b}, \mathrm{c}, \mathrm{d}, \mathrm{e}}$, Chantal Cauty ${ }^{\mathrm{a}}$, Irina Kolotuev ${ }^{\mathrm{f}, \mathrm{g}}$, Juliane

4 Floury $^{\text {a,h, }, *}$

$5 \quad{ }^{a}$ INRA, UMR1253 Science and Technology of Milk and Eggs, F-35042 Rennes, France

$6{ }^{\mathrm{b}}$ INRA, UMR782 Food Process Engineering and Microbiology, F-78850 Thiverval-Grignon,

7 France

$8{ }^{\mathrm{c}}$ AgroParisTech, UMR782 Food Process Engineering and Microbiology, F-78850 Thiverval-

9 Grignon, France

10 dINRA, UMR1318 Institut Jean-Pierre Bourgin, F-78026 Versailles, France

11 e AgroParisTech, Institut Jean-Pierre Bourgin, F-78026 Versailles, France

12 f MRic-TEM, UMS3480 Microscopy Rennes Imaging Center, F-35043 Rennes, France

13 g IGDR, UMR6290 University of Rennes 1, 2, F-35043 Rennes, France

$14{ }^{\mathrm{h}}$ Agrocampus Ouest, UMR1253 Science and Technology of Milk and Eggs, F-35042 Rennes,

15 France

16

$17{ }^{1}$ Corresponding author: Juliane Floury

18 Telephone number: +33 (0)2 234854 52; Fax number: +33 (0)2 23485578

19 E-mail: juliane.floury@agrocampus-ouest.fr 


\section{ABSTRACT}

A sound understanding of the microstructure of dairy products is of great importance in order to predict and control their properties and final quality. The aim of this study was to develop an automated image analysis procedure to characterize the microstructure of different dairy systems. A high pressure freezing coupled with freeze-substitution (HPF-FS) protocol was applied prior to transmission electron microscopy (TEM) in order to minimize any modification of the microstructure of the dairy systems investigated. The developed image analysis procedure was first validated on synthetic images of suspensions, and then on two types of concentrated milk suspensions. Microstructural data relating to casein micelles in milk suspensions were taken from the literature. The established procedure was then applied to the two corresponding rennet-induced milk gels, prepared from the same milk concentrates used for suspensions preparation. The automated image analysis procedure allowed the reliable estimation of several characteristic microstructural parameters including area fraction, porosity, boundary length per unit area, particle aggregate size, inter-particle aggregate distance and tortuosity. The relative ease of estimating these microstructural parameters from the automated image analysis method could make it useful for routine measurements of milk gels. Moreover, the method enabled a useful discrimination between two different types of milk gels. This novel approach can contribute to a better understanding of the effects of processing on the structure-property relationships in dairy products, and may be applied to other food systems.

Keywords: Transmission electron microscopy, microstructure, dairy systems, milk gels, freeze-substitution, quantitative image analysis 


\section{Introduction}

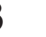

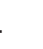

The microstructure is one of the major determining factors of flavor, physicochemical and of the functional properties of dairy products. Thus understanding the microstructure of dairy products during their manufacture and subsequent storage is of great importance in order to predict and control their properties and final quality (Gunasekaran \& Ding, 1999; ElBakry \& Sheehan, 2014).

Dairy products are principally based on caseins, which make up $80 \%$ of the protein in milk. Around $95 \%$ of the caseins in milk exist as large colloidal particles between 50 and 600 $\mathrm{nm}$ in diameter (mean $\sim 120 \mathrm{~nm}$ ), which are known as "casein micelles" (Fox \& Brodkorb, 2008). The microstructure of dairy products depends principally on the organization of these casein micelles that can change as a function of the technological treatment applied to milk. For instance, casein micelles are easily destabilized by adding rennet to milk to form a rennetinduced gel, the basis of cheese making (Lucey, 2002; Dalgleish \& Corredig, 2012). In contrast to milk, where caseins are present in suspension, milk gels form a continuous three dimensional network whose properties greatly depend on the microstructure.

The microstructure of dairy products is commonly investigated using instrumental techniques such as light or electron microscopy techniques. Light microscopy, such as Confocal Laser Scanning Microscopy (CLSM), allows the observation of dairy products with a minimum of sample preparation and with a resolution up to 0.25 microns (Fenoul, Le Denmat, Hamdi, Cuvelier, \& Michon, 2008; Morand, Guyomarc'h, Legland, \& Famelart, 2012; Ercili-Cura et al., 2013). By using this technique, it may be possible to distinguish the structure of the milk gel, but not the fine organisation of casein micelles that form its microstructure. Electron microscopy provides a resolution at a nanometer scale, making it possible to observe the organization of the gel protein network itself. Scanning Electron 
Microscopy (SEM) has already been used for investigating the microstructure of a variety of dairy products (Marchesseau, Gastaldi, Lagaude, \& Cuq, 1997; McMahon, Fife, \& Oberg, 1999; Fallico et al., 2006; Le Feunteun \& Mariette, 2007; 2008). However, SEM provides only a topographical view of the sample surface, making it difficult to quantify properties from the observed images. On the other hand, Transmission Electron Microscopy (TEM) provides observation of a slice of the sample, making it possible to investigate its internal structure. This can provide a basis for the quantitative description of the sample microstructure (Reis \& Malcata, 2011).

Conventional TEM preparation procedures include chemical fixation, dehydration and embedding, which are frequently problematic in samples with high water content. Such methods can introduce numerous artifacts that alter the relationships that exist between the structural components (Kalab, Allan-Wojtas, \& Mistry, 1995). Therefore, the use of lowtemperature methods, such as freeze-fracture replication (Büchheim, 1982; McMahon \& McManus, 1998), freeze-substitution (Goff, Verespej, \& Smith, 1999; Smith, Kakuda, \& Goff, 2000), cryo-TEM (Waninge, Nylander, Paulsson, \& Bergenstahl, 2003; 2004) and high pressure freezing coupled with freeze-substitution methods (Ramasubramanian, Webb, D'Arcy, \& Deeth, 2013) are preferable in order to preserve the original structure of the dairy sample ahead of the conventional TEM.

Nowadays, qualitative interpretations of micrographs are often no longer enough. Image analysis is necessary to also provide quantitative data for the analysis and design of food microstructure (Aguilera, Stanley, \& Baker, 2000). Such image analysis has been recently introduced into dairy research for a wide range of applications (Wium, Pedersen, \& Qvist, 2003; Impoco, Carrato, Caccamo, \& Tuminello, 2006; Rovira, Lopez, Ferrandini, \& Laencina, 2011; Geng, van den Berg, Bager, \& Ipsen, 2011; Ong, Dagastine, Kentish, \& Gras, $2011 ; 2012 ; 2013)$. 
Micrograph images of dairy samples can be quantified through the morphometry of

103 individual objects or particles (Gunasekaran \& Ding, 1999; Rovira et al., 2011; Impoco, Fucà,

104 Pasta, Caccamo, \& Licitra, 2012; Fucà, Pasta, Impoco, Caccamo, \& Licitra, 2013). When a

105 protein network cannot be easily segmented, gray level texture analysis can be used to discern

106 the variations of gray levels from confocal images (Fenoul et al., 2008; Morand et al., 2012;

107 Ercili-Cura et al., 2013). An alternative to particle-based image analysis and image texture

108 analysis is the characterization of protein network as a binary microstructure. This method

109 consists of quantifying geometrical properties of a structure that cannot be described by a set

110 of individual particles, but rather as a complex structure with voids and branches that is

111 observed in a representative window. While this approach is common in materials science

112 (Ohser \& Mücklich, 2000) and for describing porous media (Torquato, 2002), to the authors'

113 knowledge no attempt have been made to quantify the microstructure of dairy products.

114 The aim of this work was thus to develop an automated image analysis procedure to

115 characterize the microstructure of dairy systems. The proposed procedure comprised the

116 automated segmentation of the protein network from TEM micrographs, and the subsequent

117 computation of microstructural parameters by assimilating the protein network to a porous

118 media. The high pressure freezing and freeze-substitution (HPF-FS) protocol was used in

119 order to minimize modification of the microstructure of dairy systems during sample

120 preparation for TEM. Microstructural parameters considered in this study included global

121 morphological parameters (area fraction, porosity, boundary length per unit area), binary

122 image granulometry, that measures the typical sizes of particles (or of particle aggregates or

123 of voids), and a tortuosity parameter that describes the microstructure at a larger scale.

124 Tortuosity is a parameter mainly related to mass transfer properties and has been measured in

125 several porous media such as rocks, sediments, soil, zeolites, biological tissues, etc. (Suman \&

126 Ruth, 1993; Latour, Kleinberg, Mitra, \& Sotak, 1995; Zalc, Reyes, \& Iglesia, 2004; Wu, van 
127 Vliet, Frijlink, \& van der Voort Maarschalk, 2006; Shen \& Chen, 2007; Lanfrey, Kuzeljevic,

128 \& Dudukovic, 2010). Some authors have also been applying the theory of porous media to

129 food systems and have been estimating tortuosity values from diffusion coefficients in food

130 media (Crossley \& Aguilera, 2001; Sam Saguy, Marabi, \& Wallach, 2005). The determination

131 of tortuosity directly from image analysis would therefore be of great interest for

132 understanding the diffusion phenomena in dairy products.

133 The concept of measuring the above listed parameters using image analysis was first

134 tested on a synthetic image representing a suspension of micelles as might be observed under

135 conditions similar to the present study. The image analysis method was subsequently

136 validated on two concentrated milk suspensions of similar casein concentration, but produced

137 by different methods. Microstructural data relating to casein micelles in milk suspensions

138 were taken from the literature for validation. The method was then applied to the

139 corresponding concentrated milk gels, obtained by rennet-induced coagulation of the same

140 milk concentrates used for suspensions preparation, in order to show a wider application of

141 this procedure.

142

143 2. Material and Methods

144

2.1. Preparation of concentrated milk suspensions and gels

Two concentrated milk suspensions and two concentrated milk gels presenting similar

148 casein composition were produced. These dairy systems were based on two different protein

149 milk concentrates produced using either Microfiltration (MF) or Ultrafiltration (UF)

150 processes. 


\subsubsection{MF concentrate}

The aim of the membrane filtration process developed in this study was to obtain an almost pure casein concentrate, dispersed in the same aqueous phase of milk, in order to mimic as much as possible the protein composition of a real cheese. Skim milk (Entremont, Montauban de Bretagne, France) was initially filtered to remove contaminating bacteria using the microfiltration pilot equipment GP7 fitted with a $0.8 \mu \mathrm{m}$ Sterilox GP membrane. This microfiltrate was then concentrated by microfiltration using a $0.1 \mu \mathrm{m}$ aluminum Zircone membrane. This smaller pore size allowed the concentration of the casein fraction only, the size of the whey proteins in milk being sufficiently small to cross the membrane. In order to increase the concentration factor of the caseins, it was necessary to proceed to a diafiltration step of the concentrate, using the MF permeate instead of water in order to keep the same aqueous phase of milk in the final concentrate. The permeate had been previously ultrafiltrated with a $5 \mathrm{kD}$ membrane to remove the whey proteins. The overall filtration process allowed concentrating the total proteins of milk by a factor of 4.3 . Neither $\mathrm{NaCl}$ nor cream was added, leaving a non-salty and a non-fatty MF concentrate. The composition of the MF concentrate ( $\mathrm{pH}$ 6.6) is given in Table 1.

\subsubsection{UF concentrate}

The UF concentrate was produced following previously described procedures (Ulve et al., 2008; Silva, Peixoto, Lortal, \& Floury, 2013). Unlike microfiltration, the ultrafiltration process allowed the concentration of all the proteins of milk, both the caseins and the whey proteins. This UF concentrate has then the same protein composition as for some commercial cheeses obtained by using the MMV technology, such as Pavé d'Affinois (Maubois, Mocquot, \& Vassal, 1969; Maubois \& Mocquot, 1971; Maubois \& Mocquot, 1975). Overall, the total proteins of milk were concentrated in this case by a factor of 5. Once again, neither $\mathrm{NaCl}$ nor 
177 cream was added, leaving a non-salty and a non-fatty UF concentrate. The composition of the

178 UF concentrate ( $\mathrm{pH}$ 6.6) is given in Table 1.

179 The MF concentrate was used without further preparation whereas the UF concentrate

180 was heated at $93^{\circ} \mathrm{C}$ for $15 \mathrm{~min}$ (Aly et al., 2011) and then cooled using melting ice for $3 \mathrm{~min}$.

181 Sodium azide was added to both the MF and heat-treated UF concentrates at a final

182 concentration of $0.05 \%(\mathrm{wt} / \mathrm{wt})$ in order to prevent microorganism growth. About $1 \mathrm{~mL}$ of the

183 MF concentrate or of the heat-treated UF concentrate were poured into $2 \mathrm{~mL}$ Eppendorf tubes

184 and then incubated at $30^{\circ} \mathrm{C}$ for $1 \mathrm{~h}$ and then held at $19^{\circ} \mathrm{C}$ for $2 \mathrm{~h}$ to obtain the MF-suspension

185 or the UF-suspension, respectively. Both suspensions were passively aspired by using

186 cellulose microcapillary tubes with a $200 \mu \mathrm{m}$ inner diameter ahead of further preparation for

187 TEM.

188 The concentrated milk gels were produced from the same concentrates (i.e.; MF or

189 heat-treated UF concentrates). In this case, after adding sodium azide to the concentrates

$190(0.05 \% \mathrm{wt} / \mathrm{wt})$, the coagulant agent Maxiren 180 (DSM Food Specialties, Seclin, France) was

191 added giving a final concentration of $0.03 \%(\mathrm{v} / \mathrm{v})$. After homogenization, $600 \mu \mathrm{L}$ of each

192 mixture (MF or heat-treated UF concentrate + coagulant agent) was slowly poured into mini-

193 gel cassette ${ }^{\circledR}$ systems (IFR Norwich, U.K.), containing flat gold-plated specimen carriers (0.5

$194 \mathrm{~mm}$ thick, $1.5 \mathrm{~mm}$ in diameter, $200 \mu \mathrm{m}$ deep; Leica Cat \#16706898). The gel cassettes ${ }^{\circledR}$

195 systems were incubated at $30^{\circ} \mathrm{C}$ for $1 \mathrm{~h}$ to enable coagulation and then at $19^{\circ} \mathrm{C}$ for $2 \mathrm{~h}$ to

196 obtain the final gels based on each concentrate.

197

198 2.2. Transmission electron microscopy

The prepared concentrated milk suspensions and gels were frozen using a Leica EM

201 PACT2 high-pressure freezer (Leica Microsystems, Vienna, Austria). The sample carriers, 
202 cellulose microcapillary tubes or flat gold-plated specimen carriers, were pre-coated with $1 \%$

203 phosphatidylcholine (Sigma-Aldrich Ltd.) diluted in chloroform to avoid sample sticking. No 204 cryo-protecting agent was added to the samples. For the freeze-substitution step, Leica EM 205 AFS2 freeze substitution machine (Leica Microsystems, Vienna, Austria) was used. The 206 frozen samples were transferred in liquid nitrogen to a processing container equipped with a 207 flat spacer (Leica Microsystems, Vienna, Austria). The frozen samples were freeze208 substituted in $2 \%$ osmium tetroxide diluted in anhydrous acetone. After an initial incubation 209 of $8 \mathrm{~h}$ at $-90^{\circ} \mathrm{C}$ the temperature was gradually $\left(5^{\circ} \mathrm{C} /\right.$ hour $)$ raised to $-30^{\circ} \mathrm{C}$ and samples were 210 then left for another $8 \mathrm{~h}$ at this temperature. The solvent-fixative solution was replaced with 211 pre-chilled mix of ethanol 3:1 resin (epon-araldite mix; Sigma-Aldrich Ltd). The temperature 212 was then gradually brought up to room temperature and further ethanol:resin substitutions 213 were done following the resin manufacturer instructions. Thin sections $(90 \mathrm{~nm})$ of embedded 214 samples were cut with a diamond knife using a Reichert ultramicrotome. The sections were 215 contrasted with $4 \%$ aqueous solution of uranyl acetate and observed using a JEM-1400 216 Transmission Electron Microscope (JEOL Ltd., Tokyo, Japan) operated at $120 \mathrm{kV}$ 217 accelerating voltage. Digital images were acquired using the Gatan SC1000 Orius ${ }^{\circledR}$ CCD

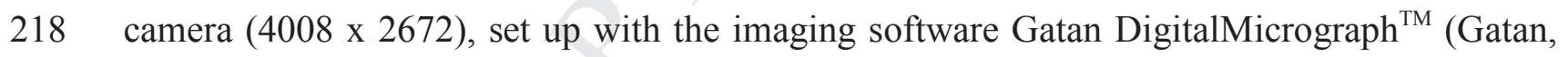
219 Pleasanton, USA).

Several TEM micrographs were taken on different parts of two independent samples 221 of each of the four dairy systems. Ten micrograph images were chosen independently for each 222 dairy system for further image analysis.

The resulting images each represented an area of $9.97 \times 6.64 \mu \mathrm{m}$ and showed the

224 microstructure of the samples at a magnification of $\mathrm{x} 20000$. Images were saved as 32-bit 225 grayscale dm3 images of $4008 \times 2670$ pixels (where 1 pixel $=2.5 \mathrm{~nm}$ ). 
Several image processing steps were necessary to automatically segment the TEM

230 images of the four dairy systems (concentrated milk suspensions and gels). These steps are

231 schematically set out in Fig. 1. Each image was normalized using a blank background image

232 (obtained without sample or resin) (Fig. 1B). This permitted the removal of intensity

233 variations over the image. Histogram normalization procedure was applied and the result was

234 converted to images based on 256 shades of gray (Fig. 1C). As artifacts could be detected on

235 some micrographs, they were removed by applying a "black top-hat" operation with a square

236 structuring element of $200 \times 200$ pixels (Fig. 1D). Black top-hat is a tool (taken from

237 mathematical morphology) that enhances dark structures smaller than the chosen structuring

238 element while removing larger variations (Soille, 2003). A smoothing operator was then

239 applied (by computing the average of pixel values in a circular neighborhood with radius of

24010 pixels) to remove the acquisition noise (Fig. 1E). The two phases were contrasted, with

241 images histograms showing two peaks (Fig. 1F). "Otsu automated threshold" is commonly

242 used for the segmentation of dairy product images (Ong et al., 2011; Hussain, Grandison, \&

243 Bell, 2012; Impoco et al., 2006) and was used for the segmentation in the present study. Otsu

244 threshold consists in identifying the threshold value that best discriminates between the two

245 phases, by minimizing the intra-class variance while maximizing inter-class variance (Otsu,

246 1979). The segmentation procedure was validated by visual inspection of the binary images

247 superimposed on the original images. 
The values of the microstructural parameters determined in the present work may

depend on several factors such as sample thickness and image processing (i.e., filter choice, by comparing microstructural parameters of concentrated milk suspensions with those of both synthetic images and data taken from the literature. Finally, the values of microstructural parameters obtained for the different dairy systems in the same conditions could be compared between them.

\subsubsection{Generation of synthetic images of a suspension}

In order to validate and help to interpret microstructural parameters, the developed image analysis method was applied on synthetic images mimicking a theoretical suspension

of micelles. A set of non-overlapping balls was generated in a $3 \mathrm{D}$ cuboid with dimensions $5 \times 5 \times 2 \mu \mathrm{m}$. The diameter of the balls was chosen as $120 \mathrm{~nm}$, corresponding to the mean diameter of casein micelles (Fox \& Brodkorb, 2008). In order to avoid edge effects, a margin of $200 \mathrm{~nm}$ was applied on all sides. The number of balls was chosen to have a numerical

265 density equal to 160 micelles $/ \mu \mathrm{m}^{3}$, corresponding to an expected number of 8000 within the

266 cuboid. This value was chosen to generate an area fraction in the synthetic images similar to

267 the one observed for milk suspensions in the present study. To avoid overlap, a minimal 268 distance of $130 \mathrm{~nm}$ was imposed between the micelle centers. The physical cut was 269 represented by a horizontal slice with thickness $90 \mathrm{~nm}$, and located in the middle of the 270 cuboid. An example of a synthetic suspension of micelles is shown on Fig. 2A. The 271 intersection of the slice with the set of balls was used to generate a planar binary image 272 representing a virtual observation of the model system. A resolution of $2.5 \mathrm{~nm}$ by pixel was 
273 used, resulting in a 2000x2000 pixels binary image (Fig. 2B). Ten images were thus generated

274 to address the variability of measurement method. Due to the thickness of the slice, some 275 micelles seemed to overlap, seemingly forming small agglomerates. Other micelles present a 276 smaller section because they were not located within the sampled slice. Matlab software was 277 used both to simulate the 3D synthetic suspensions and to generate the corresponding binary 278 images (Mathworks, Natick, MA). The Free-D software was used to produce the sample 279 image of Fig. 2A (Andrey \& Maurin (2005), http://free-d.versailles.inra.fr/html/freed.html).

\subsubsection{Global morphometry}

Global morphometry was used to determine three global microstructural parameters: area fraction, porosity, and boundary length per unit area. If the sampling slice can be assumed to have a small thickness relative to size of the structures, these parameters can be directly related to 3D properties of the network by using stereological relations.

Area fraction was defined as the ratio between dark area (i.e.; the protein matrix) with respect to the total area of the image. The dark area corresponds to the area covered by particles (for suspensions) or by particle aggregates (for gels) in the micrograph crosssections. Porosity is the complementary parameter and can be defined as the division of the

290 void area by the total image area. In the binary image, porosity was calculated as white area 291 (free space, corresponding to the aqueous phase) as a percentage of the total area (Impoco et 292 al., 2006; Rovira et al., 2011).

The boundary length per unit area is the length of the perimeter around all the particle 294 edges or boundaries (for suspensions) or particle aggregate edges or boundaries (for gels), 295 divided by the total image area. The boundary length per unit area thus measures the quantity 296 of interface between the protein phase and the aqueous phase. For a comparable area density, 297 its value will be larger for systems with small structures and/or tortuous interfaces, and 
smaller for systems with large structures and/or smooth interfaces. Boundary length was estimated by using a discretized version of Crofton formula, which consists in counting the number of intercepts with lines of various orientations, and normalized by the area of the image (Ohser \& Mücklich, 2000; Legland, Kiêu, \& Devaux, 2007).

\subsubsection{Image morphological granulometry}

The typical size of particles (or particle aggregates) and inter-particle (or inter-particle aggregate) distances were determined by applying binary image granulometry on the segmented images. Binary image granulometry is based on image transformations depending on the size of a mask referred to as a "structuring element". One of the basic transformations (taken from mathematical morphology) is the morphological opening, which effectively removes objects smaller than the structuring element (Soille, 2003). By applying openings of increasing sizes to the dairy system images, the particles (or particle aggregates) are progressively removed. The complementary transformation is morphological closing, which

312 effectively makes the voids smaller than the defined structuring element disappear. Following 313 the same process, applying closings of increasing size to the images leads to a progressive 314 elimination of the part of the image showing the voids in the structure. Thus, by either method, a particle (or void) size distribution curve is produced.

$$
g(i)=\frac{V(i)-V(i+1)}{V(\text { initial })-V(\text { final })}
$$


In the current study, the largest size (diameter) of the disk structuring element was 121

322 pixels, corresponding to about $300 \mathrm{~nm}$ on the image. To reduce computation time, structuring element diameters were considered with a step of 4 pixels. To compare granulometric curves for a set of samples, each granulometric curve was summarized by computing its geometric mean. The following weighted sum was used:

$$
m=\exp \left(\sum_{i=1}^{i m a x} g(i) * \log \left(t_{i}\right)\right)
$$

328 where $g(i)$ is the percent of grey level variation for the step $i, t_{i}$ is the size of the structuring 329 element in $\mu \mathrm{m}$ and imax is the number of closing/opening steps (Legland, Devaux, Bouchet, 330 Guillon, \& Lahaye, 2012). The geometric means of the granulometric curves obtained with 331 the openings procedure were interpreted as the average size of particles (for suspensions) or 332 particle aggregates (for gels). The geometric means of the granulometric curves obtained with 333 the closings procedure were interpreted as the average size of the aqueous phase between the 334 particles or particle aggregates.

335 A schematic representation of microstructural parameters determined for suspensions 336 and gels by using the image morphological granulometry method is given in Fig. 3.

\subsubsection{Tortuosity}

The tortuosity in every point in the aqueous phase can be defined as the ratio of the

340 shortest path (i.e.; avoiding the protein network) between two opposing borders of the image, 341 over the Euclidean distance between the same borders (Delarue \& Jeulin, 2003; Wu et al., 342 2006). An illustration of the tortuosity for a sample structure is given in Fig. 4. The 3D 343 tortuosity cannot be determined from 2D images, but 2D tortuosity can be used to 
344 quantitatively compare the microstructure of different dairy systems observed under similar 345 conditions.

346 For points belonging to aqueous phases totally included in the protein network, no

347 path can be defined to image borders. Consequently, the tortuosity over an image was defined 348 as the average value measured at points for which shortest paths could be computed. As the 349 length of the shortest path is always greater than the Euclidean distance, the tortuosity is 350 always greater than or equal to one. The tortuosity value increases with the complexity of the 351 protein network separating the aqueous phase.

352 In order to assess the variability of the tortuosity measurement, each image was 353 divided into four sub-images, and tortuosity was calculated for each sub-image. For most 354 images, the tortuosity of the complete image was similar to the average value of the sub355 images (the difference being less than the standard deviation). However, for some images, the 356 difference was greater, due to large blocks of protein network that introduce a large variability 357 in the measurement.

\subsection{Software implementation}

Image processing and analysis was performed using Fiji-win64 processing software.

362 The quantification of morphological features required the development of specific plugins,

363 which are available on request from the authors, or from the Internet at http://www.pfl-

364 cepia.inra.fr/index.php?page=ijGranulometry_en, http://www.pfl-

365 cepia.inra.fr/index.php?page=ijGeodesics_en, $\quad$ http://www.pfl-

366 cepia.inra.fr/index.php?page=imMinkowski_en. 
The mean values of microstructural parameters obtained for the four different dairy systems studied (MF-suspension, UF-suspension, MF-gel and UF-gel) were statistically compared using R software (version R i386 3.0.2) (R Foundation for Statistical Computing, Vienne, Austria). Results are presented with the mean value and the standard deviation. Oneway analysis of variance (ANOVA) and Tukey's paired comparison test were applied in order to determine which means are significantly different from one another at the $95 \%$ family-wise confidence level. The Student's test was applied in order to compare the two suspensions and the two gels.

\section{Results and Discussion}

\subsection{Image processing of TEM micrographs}

Sample images of TEM acquisition obtained by using the HPF-FS protocol are presented in Fig. 5, for both pairs of suspensions and gels. The dark phase corresponds to the protein matrix (i.e.; particles or particle aggregates). The lighter phase corresponds to the aqueous phase, formed by water, lactose, minerals and free amino acids. In all dairy systems, the particles and particle aggregates were homogeneously distributed.

The particle aggregates observed in the gels (Fig. 5C and 5D) are larger compared to 390 the individual particles in suspensions (Fig. 5A and 5B). Representative segmented TEM micrographs of the concentrated milk suspensions and

392 gels are illustrated in Fig. 6. These segmented images correspond to the TEM micrographs 393 shown in Fig. 5. The black phase of the segmented micrographs corresponds to the protein 
394 matrix (i.e.; particles or particle aggregates), while the white phase corresponds to the 395 aqueous phase.

\subsection{Quantification of microstructural parameters}

\subsubsection{Validation of the automated image analysis procedure}

Microstructural parameters were measured for the two concentrated milk suspensions

in order to validate the image processing of TEM micrographs by comparing with values

taken from the literature. Obtained values were also compared to those obtained on synthetic from TEM micrographs of the milk suspensions.

Area fractions measured from TEM micrographs were equal to $0.34 \pm 0.02$ and $0.33 \pm$

0.01 for the MF- and UF-suspensions, respectively. Area fractions did not differ statistically

$(\mathrm{p}<0.05)$ between the MF- and UF-suspensions. This fact can be explained by the same casein concentration in both suspensions $(130 \mathrm{~g} / \mathrm{kg})$.

The number of micelles in the synthetic suspension image was adjusted to obtain a value of area fraction similar to that for the real suspensions. The related value for the

synthetic images was equal to $0.338 \pm 0.005$. The other microstructural parameters can therefore be compared between synthetic and real suspensions.

414 was estimated as $116.3 \pm 0.3 \mathrm{~nm}$. This is very close to the diameter of the casein micelles, 415 validating the image analysis method in this respect. Nonetheless, the measured values on the 416 synthetic suspension images were still smaller than the real diameter of casein micelles, which 417 is attributed to the presence of smaller sections of micelles. 
Fig. 7 shows granulometric curves for the milk suspensions representing the particle

419 size distribution (Fig. 7A and 7B for MF- and UF-suspensions, respectively) and the 420 distribution of inter-particle distances (Fig. 7C and 7D for MF- and UF-suspensions, 421 respectively). A good repeatability of the particle size distributions and of inter-particle 422 distance is noted for both MF- and UF-suspensions. The corresponding mean particle size and 423 inter-particle distance values from the geometric means are given in Table 2.

424 The mean particle size was $88 \pm 3 \mathrm{~nm}$ and $99 \pm 4 \mathrm{~nm}$ for the MF- and UF-suspensions.

425 At the casein concentration used (130 g/ $/ \mathrm{gg}$, corresponding to $\sim 140 \mathrm{~g} / \mathrm{L}$ for these suspensions), 426 casein micelles are fully separated from each other, i.e., below the concentration of random427 close packing estimated as $\sim 178 \mathrm{~g} / \mathrm{L}$ (Bouchoux, Debbou, Gésan-Guiziou, Famelart, \& 428 Doublier, 2009). Casein micelles present in milk are known to have a broad size distribution 429 with diameters ranging from 50 to $500 \mathrm{~nm}$, and a mean diameter of $\sim 120 \mathrm{~nm}$ (Fox \& 430 Brodkorb, 2008). The values obtained by image analysis fall within this range of diameters 431 found for casein micelles in unconcentrated milk, but are smaller than the indicated mean 432 diameter. Similar results were reported by Srilaorkul et al. (1991), who studied the effect of 433 skim milk ultrafiltration on particle size using conventional TEM. They measured particle size 434 by observation using a Baush and Lomb measurement magnifier, counting and classifying the 435 micelles into 10 classes, each with a width of $20 \mathrm{~nm}$. They saw a decrease in mean casein 436 micelle diameter from $118 \mathrm{~nm}$ in normal milk to $87 \mathrm{~nm}$ in milk that had been concentrated 437 five times. The change in the composition of casein and minerals as a result of the 438 ultrafiltration of milk may be responsible for the change in average diameter of the casein 439 micelles.

The UF-suspension presented a mean particle size greater than that for the MF441 suspension. The larger mean particle size (of about $10 \mathrm{~nm}$ ) for the UF-suspension may be due 442 to the association of denatured whey proteins on the surface of the micelles due to the heat 
443 treatment applied to the UF concentrate (Jeurnink \& de Kruif, 1993; Anema \& Li, 2003; Nair,

444 Dalgleish, \& Corredig, 2013). Anema \& Li (2003) demonstrated that the diameter of casein

445 micelles in heated reconstituted skim milk increased by $19 \mathrm{~nm}$ as a consequence of heat

446 treatments. For the concentrated milk studied in the same work, prepared by subjecting milk

447 to a combination of ultrafiltration and microfiltration techniques, an overall increase of $5 \mathrm{~nm}$

448 was observed when samples at $\mathrm{pH} 6.55$ were heated for $45 \mathrm{~min}$ at $90^{\circ} \mathrm{C}$. These values are

449 comparable to the increase of about $10 \mathrm{~nm}$ of mean particle size found in the current study for

450 the (heat-treated) UF-suspension.

451 The mean inter-particle distance obtained from the image analysis was $123 \pm 5 \mathrm{~nm}$ and

$452132 \pm 2 \mathrm{~nm}$ for the MF- and UF-suspensions, respectively. These values are smaller than

453 those predicted from the synthetic suspension $(153 \pm 3 \mathrm{~nm})$. This may be explained by the

454 differences in the diameter distribution: as real suspensions contain a larger number of small

455 micelles the mean free distance will be less. The mean free distance between casein micelles

456 in unconcentrated milk is reported as around $240 \mathrm{~nm}$ (Fox \& Brodkorb, 2008). As expected,

457 the mean inter-particle distances between the casein micelles would be smaller in the

458 concentrated milk suspensions than in milk $(25 \mathrm{~g} / \mathrm{L})$ due to the higher casein concentration

$459(130 \mathrm{~g} / \mathrm{kg}$, i.e. around $140 \mathrm{~g} / \mathrm{L})$ as a result of the membrane technology (microfiltration or

460 ultrafiltration processes) applied. It is known that when the concentration of total solids in

461 skim milk increases (e.g. during ultrafiltration), the distance between the casein micelles

462 decreases due to the increased volume fraction (Karlsson, Ipsen, Schrader, \& Ardö, 2005).

463 The images of the MF- and UF-suspensions presented similar area fraction values

464 whereas the particle size and inter-particle distance values were statistically different. The

465 mean inter-particle distance was greater for the UF-suspension (when compared with the MF-

466 suspension) that counteracted, to some extent, the effect of the larger mean particle size. 
The MF-suspension images presented a boundary length per unit area of $13.3 \pm 0.5$

$468 \mu \mathrm{m} / \mu \mathrm{m}^{2}$, and the UF-suspension a value of $12.1 \pm 0.2 \mu \mathrm{m} / \mu \mathrm{m}^{2}$. This parameter is a measure of

469 the quantity of interface between the protein phase (black phase) and the aqueous phase

470 (white phase). For comparison, the values measured for the synthetic suspension images were

$471 \quad 11.5 \pm 0.2 \mu \mathrm{m} / \mu \mathrm{m}^{2}$. This may be explained by the fact that synthetic suspensions are more

472 regular than real ones. The value was significantly larger for the MF-suspension than for the

473 UF-suspension. This result may have been expected because a suspension with small particles

474 (MF-suspension) will have a greater interface (between the particles and the aqueous phase)

475 and thus a larger boundary length per unit area value. As both suspensions have the same area

476 fraction, the observed difference depends on the regularity of the interface. Assuming a

477 suspension of spherical particles, an interpretation is that the MF-suspension is composed of

478 smaller particles compared with the UF-suspension.

The tortuosity was $1.08 \pm 0.01$ for the MF-suspension and $1.06 \pm 0.01$ for the UF-

suspension. These values were not significantly different $(p<0.05)$ but they were a little bit

481 larger than that for the synthetic suspensions $(1.043 \pm 0.001)$. It can be observed that 482 tortuosity value increases when mean distance between micelles decreases, and when 483 boundary length per unit area increases.

484 Overall, the microstructural parameter values predicted for concentrated milk suspensions by the image analysis procedure were in agreement with literature findings and also with results obtained for a synthetic suspension. This fact allowed us to validate the 487 image processing of TEM micrographs. 


\subsubsection{Application of the automated image analysis procedure to milk gels}

The image analysis procedure validated previously for the two types of concentrated milk suspensions was then applied to their corresponding gels, which had been obtained by rennet-induced coagulation, in order to determine their microstructural parameters.

The microstructure of milk gels is more complex than that for suspensions and depends on several factors such as the type of coagulation and the treatment applied to the milk concentrate prior to the coagulation step. It is well known that the addition of chymosin cleaves a specific bond of the $\kappa$-casein on the surface of the micelles. This reduces the steric and electrostatic repulsion between the micelles, and the destabilized micelles thus begin to aggregate to form the gel (Mellema, Heesakkers, van Opheusden, \& van Vliet, 2000).

Table 3 sets out the values for the microstructural parameters obtained from the TEM images of MF- and UF-gels.

The mean area fractions were $0.49 \pm 0.03$ and $0.50 \pm 0.02$ for MF- and UF-gels, respectively, which were significantly $(p<0.05)$ larger than the values obtained for the related suspensions $(0.34 \pm 0.02$ and $0.33 \pm 0.01$ for MF- and UF-suspensions, respectively). However, similar area fraction values should be expected for concentrated milk suspensions and gels presenting the same casein concentration. This unexpected result may be explained by the aggregation of casein micelles in the gel which could induce changes in the apparent density of particles on the TEM images, due to the slice thickness of the sample.

Curds from heat-treated milks tend to be weak, ragged in appearance with a poor matting ability and poor fusion of the gel network, giving rise to more porous matrices (Singh \& Waungana, 2001). However, in the present study, the UF-gel (made from heat-treated UF concentrate) presented the same porosity compared with the MF-gel (about 0.50). This fact can be explained by the ultrafiltration of the milk prior to coagulation in the case of the UFgel. It is known that gels formed from UF concentrates are much firmer than the 
517 corresponding curds produced from unconcentrated milks at comparable levels of $\beta$ -

518 lactoglobulin denaturation and association (Singh \& Waungana, 2001). This result is 519 interesting because gels obtained from different technological treatments but with the same 520 casein composition have a similar porosity. Thus, heat treatment in combination with 521 concentration processes such as ultrafiltration may yield opportunities to correct curd 522 properties.

Fig. 8 shows granulometric curves obtained by applying the opening procedure (Fig. $8 \mathrm{~A}$ and $8 \mathrm{~B}$ for MF- and UF-gels, respectively), representing the distribution of particle aggregate sizes and by the closing procedure (Fig. 8C and 8D for MF- and UF-gels, respectively), representing the distribution of inter-particle aggregate distances obtained from TEM micrographs. Fig. 8 demonstrates the good repeatability of the distribution of particle aggregate size and inter-particle aggregate distance values obtained from different TEM micrographs of the MF- and UF-gels. Values for these same parameters are set out in Table 3. than the mean particle aggregate size in UF-gel, $135 \pm 8 \mathrm{~nm}$. Concerning the rennet-induced 532 gels, it is known that in milk that has been heated, the $\kappa$-casein is broken down by chymosin 533 (as it is in unheated milk), but that the micelles do not aggregate well (Kethireddipalli, Hill, \& Dalgleish, 2011). This is due to the presence of denatured whey proteins on the micellar surface, which may hinder the close approach of the potentially interacting sites on the micelles (Dalgleish \& Corredig, 2012). Waungana, Singh, \& Bennett (1996) observed that the 537 denaturation of individual whey proteins and their association with the casein micelles 538 resulted in prolonged gelation times and reduced gel firmness in gels produced from heat539 treated UF milk (UHT system; $80^{\circ} \mathrm{C}$ to $140^{\circ} \mathrm{C}$ for $4 \mathrm{~s}$ ) due to the formation of a limited 540 number of reactive sites at the micellar surface. It may thus follow that the denatured whey 541 proteins associated on the micellar surface in the UF concentrate prevented the close approach 
542 of casein micelles, resulting in smaller particle aggregates in the (heat-treated) UF-gel when

543 compared with the MF-gel.

As expected, the mean particle aggregate size is larger in the two gels studied compared with the mean particle size in the corresponding suspensions. This may be explained by the aggregation of casein micelles in gels as a consequence of the addition of the coagulant agent (rennet) (Walstra, Bloomfield, Jason Wei, \& Jenness, 1981). for the MF-gel, significantly greater than the mean value of $131 \pm 7 \mathrm{~nm}$ obtained for the UFgel. The MF-gel contained particle aggregates and inter-particle aggregate distances greater than those found in the UF-gel. These results are consistent with the boundary length unit area values obtained for these gels.

The boundary length per unit area for the UF-gel was $10.7 \pm 0.7 \mu \mathrm{m} / \mu \mathrm{m}^{2}$, significantly 554 larger $(\mathrm{p}<0.05)$ than the value found for the MF-gel, $9.5 \pm 0.3 \mu \mathrm{m} / \mu^{2}$. The boundary length per unit area values obtained for the gels were larger when the particle aggregate sizes were smaller (Table 3). This result was expected because matrices with smaller particle aggregates 557 present more interfaces (particle aggregates/aqueous phase).

Values of boundary length per unit area were significantly larger $(p<0.05)$ in the gels 559 when compared to suspensions. This result was also expected because particle sizes in 560 suspensions were found to be significantly smaller $(p<0.05)$ than particle aggregate sizes in 561 gels. Therefore, in suspensions, more interfaces (particle/aqueous phase) were present, 562 resulting in bigger values of boundary length per unit area values. Tortuosity values were similar for the two concentrated milk gels $(1.5 \pm 0.2$ and $1.5 \pm$ 5640.2 for MF- and UF-gels, respectively). These values are much larger than for the suspensions. This corresponds to the increase in the aggregate size, which leads to longer 
566 paths between given points. In this study, the tortuosity value could not enable discrimination

567 between different gel microstructures but with similar casein composition.

\section{Conclusions}

An automated image analysis procedure for microstructural characterization of dairy systems was developed. The procedure was first applied to models of synthetic suspensions, and then on milk suspensions (with comparison with published data) to validate the methodology. The computerized image analysis method enabled an easy measurement of a series of microstructural parameters of milk gels, which makes it especially useful for routine measurements.

The measurements of the area fraction (and hence of the sample porosity) were similar for the MF- and UF-suspensions, and for the MF- and UF-gels. The image analysis procedure made it possible to quantify differences of microstructure independently of the area fraction. Binary image granulometry measures particle size distribution that can also be represented by

581 an average particle size. In a similar way, the distribution of distances between particles can

582 be represented by an average value. These two measurements can describe dairy systems by using parameters that can be easily interpreted and compared.

The measurement of boundary length per unit area indicates the complexity of the matrix microstructure, without making the assumption that the system is a collection of particles. In case of particles systems with a similar area fraction, this parameter seems to be 587 correlated with the average particle size. expected to be related to diffusion properties. In this study, the measured values were different for suspensions and gels, but no difference could be discerned between the two gels 
studied (obtained with different preparation methods). Tortuosity is difficult to measure when

592 the area fraction of the solid phase is large: when the aggregates are large, the probability of 593 observing non-connected aqueous phases increases. An alternative could be to allow the 594 computation of geodesic distances in both phases but using different propagation speeds (Wu 595 et al., 2006), or to consider the tortuosity over a limited distance.

It was demonstrated that the image analysis method for the estimation of microstructural parameters was able to differentiate between dairy systems of similar composition, but obtained from different processes.

For a better understanding of the microstructure of dairy systems, modeling approaches might be considered. In this study, we have simulated binary images similar to 601 suspension images, with the objective of validating the image analysis methodology. 602 However, the microstructure of milk gels is much more complex and involves a variety of 603 physical and chemical processes. Several modeling approaches have already been undertaken

604 by other authors to reconstruct the microstructure based on 2D or 3D observations (Yeong \& 605 Torquato, 1998; Kumar, Briant, \& Curtin, 2006; Nisslert, Kvarnström, Loren, Nyden, \& 606 Rudemo, 2007; Jiang, Chen, \& Burkhart, 2013). Similar approaches could be investigated for 607 dairy systems.

The developed image analysis procedure enables new insights into the characterization

609 of the microstructure of dairy systems. This approach, which was applied to milk gels, might 610 be adapted and extended to other food systems.

611 This procedure can also contribute to a better understanding of the effects of 612 processing on the structure-property relationships in dairy products. For instance, further work 613 might focus on coupling measurements obtained by image analysis, which describe the 614 microstructure of milk gels, to physical phenomena such as diffusion properties. 


\section{Acknowledgments}

617

618 The authors would like to thank Antoine Bouchoux (INSA, Toulouse, France) and 619 Marie-Hélène Famelart (INRA, Rennes, France) for their help and suggestions during the 620 writing of this paper. The authors also wish to thank the members of MRic TEM facility 621 (Rennes, France) for their help with the TEM observations. The authors acknowledge with 622 gratitude the financial support received both from the Brittany Regional Council and from 623 INRA Rennes (France). 
625

626

627

628

629

630

631

632

633

634

635

636

637

638

639

640

641

642

643

644

645

646

647

648

649

650

Aguilera, J. M., Stanley, D. W., \& Baker, K. M. (2000). New dimensions in microstructure of food products. Trends in Food Science \& Technology, 11(1), 3-9.

Aly, S., Floury, J., Famelart, M. H., Madec, M. N., Dupont, D., Le Gouar, Y. et al. (2011). Nisin quantification by ELISA allows the modeling of its apparent diffusion coefficient in model cheeses. Journal of Agricultural and Food Chemistry, 59(17), 9484-9490.

Andrey, P. \& Maurin, Y. (2005). Free-D: an integrated environment for three-dimensional reconstruction from serial sections. Journal of Neuroscience Methods, 145(1-2), 233244.

Anema, S. G. \& Li, Y. (2003). Association of denatured whey proteins with casein micelles in heated reconstituted skim milk and its effect on casein micelle size. Journal of Dairy Research, 70, 73-83.

Bouchoux, A., Debbou, B., Gésan-Guiziou, G., Famelart, M.-H., \& Doublier, J.-L. (2009). Rheology and phase behavior of dense casein micelle dispersions. The Journal of Chemical Physics, 131(16).

Büchheim, W. (1982). Aspects of sample preparation for freeze-fracture/freeze-etch studies of proteins and lipids in food systems: a review. Food Microstructure, 1(2), 189-208.

Crossley, J. I. \& Aguilera, J. M. (2001). Modeling the effect of microstructure on food extraction. Journal of Food Process Engineering, 24(3), 161-177.

Dalgleish, D. G. \& Corredig, M. (2012). The structure of the casein micelle of milk and its changes during processing. Annual Review of Food Science and Technology, 3(1), 449-467.

Delarue, A. \& Jeulin, D. (2003). 3D morphological characterization of composite materials with spherical aggregates. Image Analysis and Stereology, 22, 153-161.

El-Bakry, M. \& Sheehan, J. (2014). Analysing cheese microstructure: A review of recent developments. Journal of Food Engineering, 125, 84-96. 
Ercili-Cura, D., Lille, M., Legland, D., Gaucel, S., Poutanen, K., Partanen, R. et al. (2013). Structural mechanisms leading to improved water retention in acid milk gels by use of transglutaminase. Food Hydrocolloids, 30(1), 419-427.

Fallico, V., Tuminello, L., Pediliggieri, C., Horne, J., Carpino, S., \& Licitra, G. (2006). Proteolysis and microstructure of Piacentinu Ennese cheese made using different farm technologies. Journal of Dairy Science, 89(1), 37-48.

Fenoul, F., Le Denmat, M., Hamdi, F., Cuvelier, G., \& Michon, C. (2008). Technical Note: Confocal Scanning Laser Microscopy and quantitative image analysis: Application to cream cheese microstructure investigation. Journal of Dairy Science, 91(4), 13251333.

Fox, P. F. \& Brodkorb, A. (2008). The casein micelle: Historical aspects, current concepts and significance. International Dairy Journal, 18(7), 677-684.

Fucà, N., Pasta, C., Impoco, G., Caccamo, M., \& Licitra, G. (2013). Microstructural properties of milk fat globules. International Dairy Journal, 31(1), 44-50.

Geng, X. L., van den Berg, F. W. J., Bager, A. N., \& Ipsen, R. (2011). Dynamic visualization and microstructure of syneresis of cheese curd during mechanical treatment. International Dairy Journal, 21(9), 711-717.

Goff, H. D., Verespej, E., \& Smith, A. K. (1999). A study of fat and air structures in ice cream. International Dairy Journal, 9(11), 817-829.

Gunasekaran, S. \& Ding, K. (1999). Three-dimensional characteristics of fat globules in cheddar cheese. Journal of Dairy Science, 82(9), 1890-1896.

Hussain, I., Grandison, A. S., \& Bell, A. E. (2012). Effects of gelation temperature on Mozzarella-type curd made from buffalo and cows milk. 1: Rheology and microstructure. Food Chemistry, 134(3), 1500-1508.

Impoco, G., Carrato, S., Caccamo, M., \& Tuminello, L. (2006). Quantitative analysis of cheese microstructure using SEM imagery. In SIMAI 2006 Minisymposium: Image Analysis Methods for Industrial Application. 
Impoco, G., Fucà, N., Pasta, C., Caccamo, M., \& Licitra, G. (2012). Quantitative analysis of nanostructures shape and distribution in micrographs using image analysis. Computers and Electronics in Agriculture, 84, 26-35.

Jeurnink, T. J. M. \& de Kruif, K. G. (1993). Changes in milk on heating: viscosity measurements. Journal of Dairy Research, 60(2), 139-150.

Jiang, G. Z., Chen, W., \& Burkhart, C. (2013). Efficient 3D porous microstructure reconstruction via Gaussian random field and hybrid optimization. Journal of Microscopy, 252(2), 135-148.

Kalab, M., Allan-Wojtas, P., \& Mistry, V. V. (1995). Microscopy and other imaging techniques in food structure analysis. Trends in Food Science \& Technology, 6, 32103218.

Karlsson, A. O., Ipsen, R., Schrader, K., \& Ardö, Y. (2005). Relationship between physical properties of casein micelles and rheology of skim milk concentrate. Journal of Dairy Science, 88(11), 3784-3797.

Kethireddipalli, P., Hill, A. R., \& Dalgleish, D. G. (2011). Interaction between casein micelles and whey protein/kappa-casein complexes during renneting of heat-treated reconstituted skim milk powder and casein micelle/serum mixtures. Journal of Agricultural and Food Chemistry, 59(4), 1442-1448.

Kumar, H., Briant, C. L., \& Curtin, W. A. (2006). Using microstructure reconstruction to model mechanical behavior in complex microstructures. Mechanics of Materials, $38(8-10), 818-832$.

Lanfrey, P. Y., Kuzeljevic, Z. V., \& Dudukovic, M. P. (2010). Tortuosity model for fixed beds randomly packed with identical particles. Chemical Engineering Science, 65(5), 1891-1896.

Latour, L. L., Kleinberg, R. L., Mitra, P. P., \& Sotak, C. H. (1995). Pore-size distributions and tortuosity in heterogeneous porous media. Journal of Magnetic Resonance, Series A, 112(1), 83-91. 
Le Feunteun, S. \& Mariette, F. (2007). Impact of casein gel microstructure on self-diffusion coefficient of molecular probes measured by ${ }^{1} \mathrm{H}$ PFG-NMR. Journal of Agricultural and Food Chemistry, 55(26), 10764-10772.

Le Feunteun, S. \& Mariette, F. (2008). PFG-NMR techniques provide a new tool for continuous investigation of the evolution of the casein gel microstructure after renneting. Macromolecules, 41(6), 2071-2078.

Legland, D., Devaux, M. F., Bouchet, B., Guillon, F., \& Lahaye, M. (2012). Cartography of cell morphology in tomato pericarp at the fruit scale. Journal of Microscopy, 247(1), 78-93.

Legland, D., Kiêu, K., \& Devaux, M. F. (2007). Computation of Minkowski measures on 2D and 3D binary images. Image Analysis and Stereology, 26(6), 83-92.

Lucey, J. A. (2002). Formation and physical properties of milk protein gels. Journal of Dairy Science, 85(2), 281-294.

Marchesseau, S., Gastaldi, E., Lagaude, A., \& Cuq, J. L. (1997). Influence of pH on protein interactions and microstructure of process cheese. Journal of Dairy Science, 80(8), 1483-1489.

Maubois, J. L. \& Mocquot, G. (1971). Préparation de fromage à partir de "pré-fromage liquide" obtenu par ultrafiltration du lait. Lait, 51(508), 495-533.

Maubois, J. L. \& Mocquot, G. (1975). Application of membrane ultrafiltration to preparation of various types of cheese. Journal of Dairy Science, 58(7), 1001-1007.

Maubois, J. L., Mocquot, G., \& Vassal, L. (1969). A method for processing milk and milk products. [2052121]. French.

McMahon, D. J., Fife, R. L., \& Oberg, C. J. (1999). Water partitioning in Mozzarella cheese and its relationship to cheese meltability. Journal of Dairy Science, 82(7), 1361-1369.

McMahon, D. J. \& McManus, W. R. (1998). Rethinking casein micelle structure using electron microscopy. Journal of Dairy Science, 81(11), 2985-2993. 
Mellema, M., Heesakkers, J. W. M., van Opheusden, J. H. J., \& van Vliet, T. (2000). Structure and scaling behavior of aging rennet-induced casein gels examined by confocal microscopy and permeametry. Langmuir, 16(17), 6847-6854.

Morand, M., Guyomarc'h, F., Legland, D., \& Famelart, M. H. (2012). Changing the isoelectric point of the heat-induced whey protein complexes affects the acid gelation of skim milk. International Dairy Journal, 23(1), 9-17.

Nair, P. K., Dalgleish, D. G., \& Corredig, M. (2013). Colloidal properties of concentrated heated milk. Soft Matter, 9(14), 3815-3824.

Nisslert, R., Kvarnström, M., Loren, N., Nyden, M., \& Rudemo, M. (2007). Identification of the three-dimensional gel microstructure from transmission electron micrographs. Journal of Microscopy, 225(1), 10-21.

Ohser, J. \& Mücklich, F. (2000). Statistical analysis of microstructures in materials sciences. (1th ed.). Chichester: John Wiley \& Sons.

Ong, L., Dagastine, R. R., Kentish, S. E., \& Gras, S. L. (2011). Microstructure of milk gel and cheese curd observed using cryo scanning electron microscopy and confocal microscopy. Food Science and Technology, 44(5), 1291-1302.

Ong, L., Dagastine, R. R., Kentish, S. E., \& Gras, S. L. (2012). The effect of pH at renneting on the microstructure, composition and texture of Cheddar cheese. Food Research International, 48(1), 119-130.

Ong, L., Dagastine, R. R., Kentish, S. E., \& Gras, S. L. (2013). The effect of calcium chloride addition on the microstructure and composition of Cheddar cheese. International Dairy Journal, 33(2), 135-141.

Otsu, N. (1979). A threshold selection method from gray-level histograms. IEEE Transactions on Systems, Man, and Cybernetics, 9(1), 62-66.

Ramasubramanian, L., Webb, R., D'Arcy, B., \& Deeth, H. C. (2013). Characteristics of a calcium-milk coagulum. Journal of Food Engineering, 114(2), 147-152.

Reis, P. J. M. \& Malcata, F. X. (2011). Ripening-related changes in Serra da Estrela cheese: A stereological study. Journal of Dairy Science, 94(3), 1223-1238. 
Rovira, S., Lopez, M. B., Ferrandini, E., \& Laencina, J. (2011). Hot topic: Microstructure quantification by scanning electron microscopy and image analysis of goat cheese curd. Journal of Dairy Science, 94(3), 1091-1097.

Sam Saguy, I., Marabi, A., \& Wallach, R. (2005). New approach to model rehydration of dry food particulates utilizing principles of liquid transport in porous media. Trends in Food Science \& Technology, 16(11), 495-506.

Shen, L. \& Chen, Z. (2007). Critical review of the impact of tortuosity on diffusion. Chemical Engineering Science, 62(14), 3748-3755.

Silva, J. V. C., Peixoto, P. D. S., Lortal, S., \& Floury, J. (2013). Transport phenomena in a model cheese: The influence of the charge and shape of solutes on diffusion. Journal of Dairy Science, 96(10), 6186-6198.

Singh, H. \& Waungana, A. (2001). Influence of heat treatment of milk on cheesemaking properties. International Dairy Journal, 11(4-7), 543-551.

Smith, A. K., Kakuda, Y., \& Goff, H. D. (2000). Changes in protein and fat structure in whipped cream caused by heat treatment and addition of stabilizer to the cream. Food Research International, 33(8), 697-706.

Soille, P. (2003). Morphological Image Analysis: Principles and Applications. (2 ed.). Secaucus, NJ, USA: Springer-Verlag New York, Inc.

Srilaorkul, S., Ozimek, L., Ooraikul, B., Hadziyev, D., \& Wolfe, F. (1991). Effect of ultrafiltration of skim milk on casein micelle size distribution in retentate. Journal of Dairy Science, 74(1), 50-57.

Suman, R. \& Ruth, D. (1993). Formation factor and tortuosity of homogeneous porous media. Transp Porous Med, 12(2), 185-206.

Torquato, S. (2002). Random heterogeneous materials: microstructure and macroscopic properties. New York: Springer-Verlag.

Ulve, V. M., Monnet, C., Valence, F., Fauquant, J., Falentin, H., \& Lortal, S. (2008). RNA extraction from cheese for analysis of in situ gene expression of Lactococcus lactis. Journal of Applied Microbiology, 105(5), 1327-1333. 
Walstra, P., Bloomfield, V. A., Jason Wei, G., \& Jenness, R. (1981). Effect of chymosin action on the hydrodynamic diameter of casein micelles. Biochimica et Biophysica Acta (BBA) - Protein Structure, 669(2), 258-259.

Waninge, R., Kalda, E., Paulsson, M., Nylander, T., \& Bergenstahl, B. (2004). Cryo-TEM of isolated milk fat globule membrane structures in cream. Physical Chemistry and Chemical Physics, 6, 1518-1523.

Waninge, R., Nylander, T., Paulsson, M., \& Bergenstahl, B. (2003). Milk membrane lipid vesicle structures studied with cryo-TEM. Colloids and Surfaces B: Biointerfaces, $31(1-4), 257-264$.

Waungana, A., Singh, H., \& Bennett, R. J. (1996). Influence of denaturation and aggregation of beta-lactoglobulin on rennet coagulation properties of skim milk and ultrafiltered milk. Food Research International, 29(8), 715-721.

Wium, H., Pedersen, P. S., \& Qvist, K. B. (2003). Effect of coagulation conditions on the microstructure and the large deformation properties of fat-free Feta cheese made from ultrafiltered milk. Food Hydrocolloids, 17(3), 287-296.

Wu, Y. S., van Vliet, L. J., Frijlink, H. W., \& van der Voort Maarschalk, K. (2006). The determination of relative path length as a measure for tortuosity in compacts using image analysis. European Journal of Pharmaceutical Sciences, 28(5), 433-440.

Yeong, C. L. Y. \& Torquato, S. (1998). Reconstructing random media. Physical Review e, 57(1), 495-506.

Zalc, J. M., Reyes, S. C., \& Iglesia, E. (2004). The effects of diffusion mechanism and void structure on transport rates and tortuosity factors in complex porous structures. Chemical Engineering Science, 59(14), 2947-2960. 


\section{Table Captions}

\section{Table 1}

Composition of the MF and UF concentrates.

\section{Table 2}

Values of parameters characterizing the microstructure of two concentrated milk suspensions (MF- and UF-suspensions) obtained from image analysis on binary micrographs ${ }^{1}$.

\section{Table 3}

Values of parameters characterizing the microstructure of two concentrated milk gels (MFand UF-gels) obtained from image analysis on binary micrographs ${ }^{1}$. 


\section{Figure Captions}

Fig. 1. Schematic representation of the automated segmentation procedure. The original TEM micrograph $(\mathrm{A})$ is divided by a background image $(\mathrm{B})$ to obtain a normalized image $(\mathrm{C})$. The protein network is enhanced using a black top-hat filter (D), and smoothed to remove acquisition noise (E). Gray level histogram of the image, showing two peaks corresponding to the dark and white phases (F). The application of the Otsu threshold results in a binary image showing the protein phase as black and the void (aqueous) phase as white (G).

Fig. 2. Generation of a synthetic suspension of micelles. (A) 3D representation of a sample of the system of spheres (red) together with the region corresponding to the thick section (blue). (B) Sample binary image obtained by the intersection of the thick section with the system of spheres, projected along the $\mathrm{z}$ direction.

Fig. 3. Schematic representation of the microstructural parameters determined for dairy systems (suspensions and gels) by the image morphological granulometry method.

Fig. 4. Graphical illustration of tortuosity through a given point in a synthetic binary structure, computed as the ratio of the shortest lengths to borders (dashed line) over the image width (black line).

Fig. 5. TEM micrographs of concentrated milk suspensions and gels at 20000x magnification. (A) MF-suspension; (B) UF-suspension; (C) MF-gel; (D) UF-gel. 
Fig. 6. Representative segmented TEM micrographs (binarised images) of concentrated milk suspensions and the related gels. (A) MF-suspension; (B) UF-suspension; (C) MF-gel; (D) UF-gel. These binarised images correspond to the TEM micrographs showed in Fig. 4.

Fig. 7. Distribution of particle sizes in TEM micrographs of (A) MF-suspension and (B) UFsuspension; Distribution of inter-particle distances in TEM micrographs of (C) MFsuspension and (D) UF-suspension.

Fig. 8. Distribution of particle aggregate sizes in TEM micrographs of (A) MF-gel and (B) UF-gel; Distribution of inter-particle aggregate distances in TEM micrographs of (C) MF-gel and (D) UF-gel. 


\begin{tabular}{cccccc}
\hline Product & $\begin{array}{c}\text { Dry matter } \\
(\mathrm{g} / \mathrm{kg})\end{array}$ & $\begin{array}{c}\text { Caseins } \\
(\mathrm{g} / \mathrm{kg})\end{array}$ & $\begin{array}{c}\text { Whey proteins } \\
(\mathrm{g} / \mathrm{kg})\end{array}$ & $\begin{array}{c}\text { Lactose and Minerals } \\
(\mathrm{g} / \mathrm{kg})\end{array}$ & $\begin{array}{c}\text { Other } \\
(\mathrm{g} / \mathrm{kg})\end{array}$ \\
\hline MF concentrate & 196 & 130.3 & 4.4 & 60.1 & 1.6 \\
UF concentrate & 223 & 130.7 & 27.3 & 63.1 & 1.8 \\
\hline
\end{tabular}




\begin{tabular}{lcc}
\hline Parameter & MF-suspension & UF-suspension \\
\hline Area fraction & $0.34 \pm 0.02$ & $0.33 \pm 0.01$ \\
Porosity & $0.66 \pm 0.02$ & $0.67 \pm 0.01$ \\
Boundary length per unit area $\left(\mu \mathrm{m} / \mu \mathrm{m}^{2}\right)$ & $13.3 \pm 0.5$ & $12.1 \pm 0.2^{*}$ \\
Particle size $(\mathrm{nm})$ & $88 \pm 3$ & $99 \pm 4^{*}$ \\
Inter-particle distance $(\mathrm{nm})$ & $123 \pm 5$ & $132 \pm 2^{*}$ \\
Tortuosity & $1.08 \pm 0.01$ & $1.06 \pm 0.01$ \\
\hline
\end{tabular}

${ }^{\mathrm{T}}$ The results are expressed as the mean \pm standard deviation of the mean $(\mathrm{n}=10)$.

${ }^{*}$ The means within a single row are significantly different $(\mathrm{p}<0.05)$. 


\begin{tabular}{lcc}
\hline Parameter & MF-gel & UF-gel \\
\hline Area fraction & $0.49 \pm 0.03$ & $0.50 \pm 0.02$ \\
Porosity & $0.51 \pm 0.03$ & $0.50 \pm 0.02$ \\
Boundary length per unit area $\left(\mu \mathrm{m} / \mu \mathrm{m}^{2}\right)$ & $9.5 \pm 0.3$ & $10.7 \pm 0.7^{*}$ \\
Particle aggregate size $(\mathrm{nm})$ & $141 \pm 3$ & $135 \pm 8^{*}$ \\
Inter-particle aggregate distance $(\mathrm{nm})$ & $147 \pm 5$ & $131 \pm 7^{*}$ \\
Tortuosity & $1.5 \pm 0.2$ & $1.5 \pm 0.2$ \\
\hline
\end{tabular}

${ }^{\mathrm{T}}$ The results are expressed as the mean \pm standard deviation of the mean $(\mathrm{n}=10)$.

*The means within a single row are significantly different $(\mathrm{p}<0.05)$. 
A

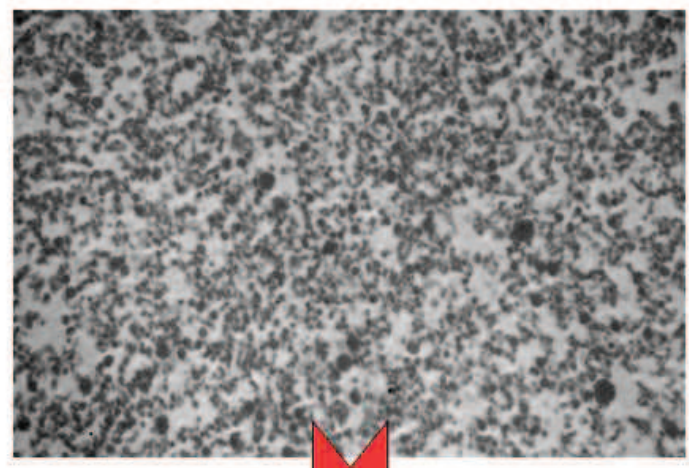

B

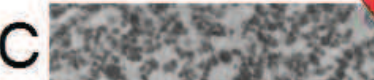

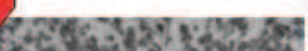

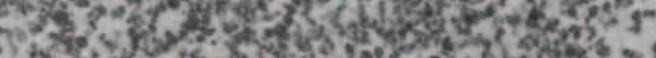
chis s.t.

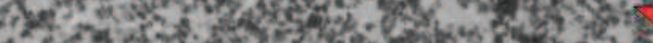

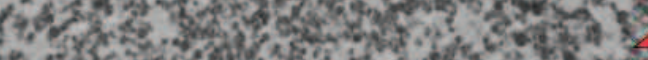

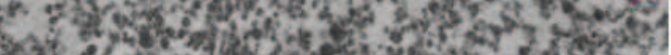

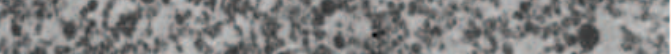

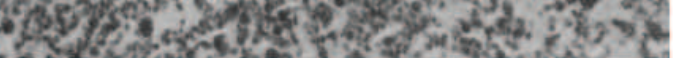
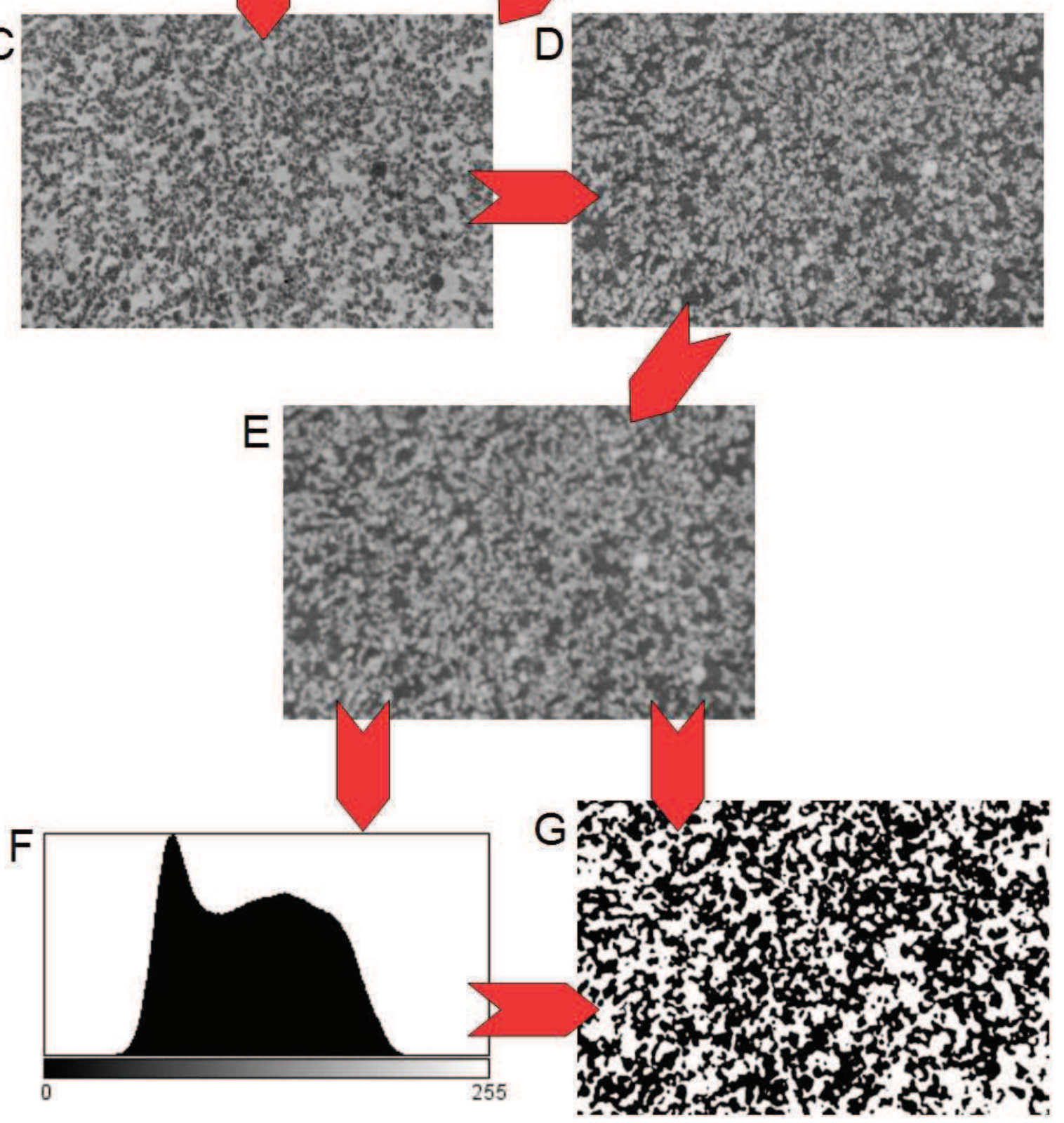


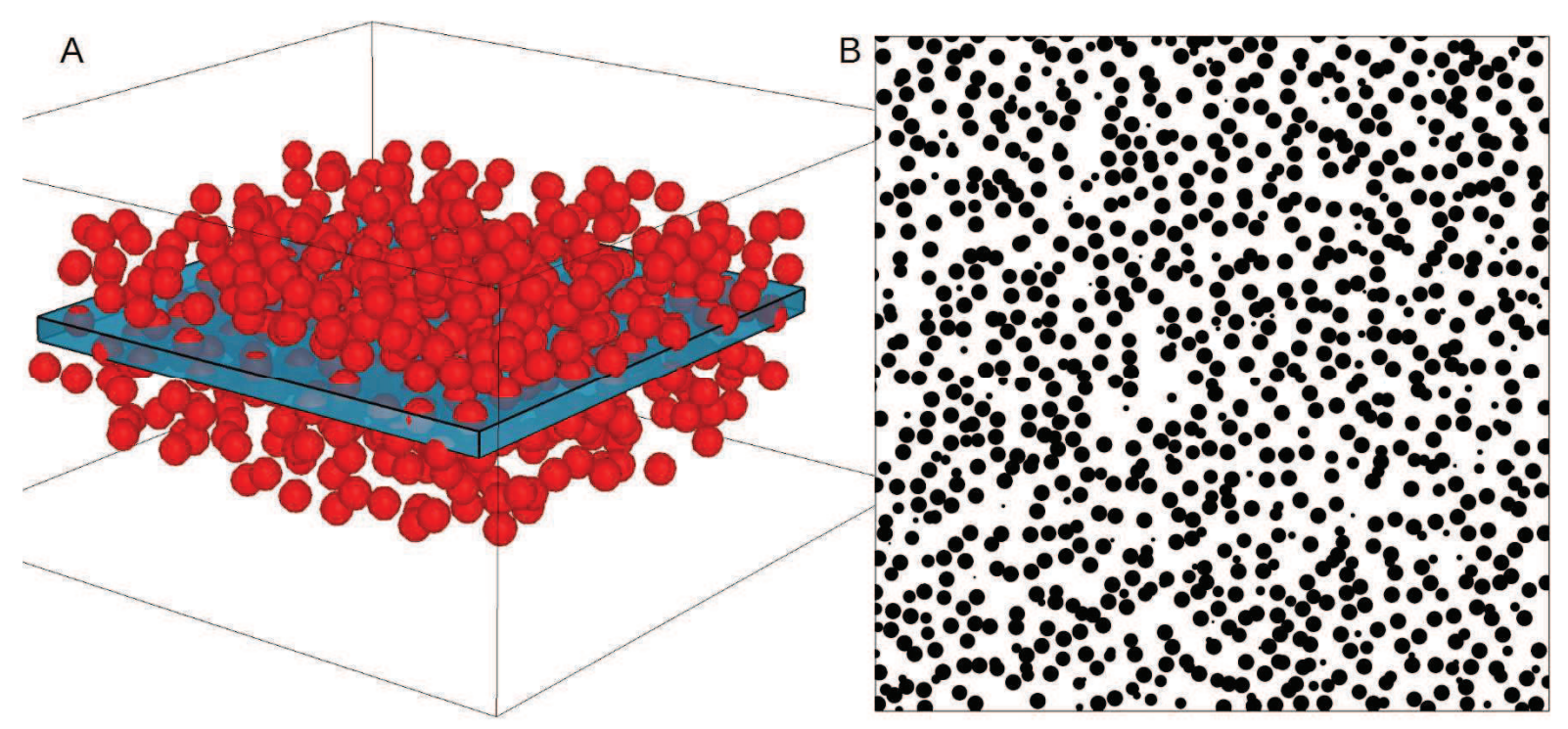



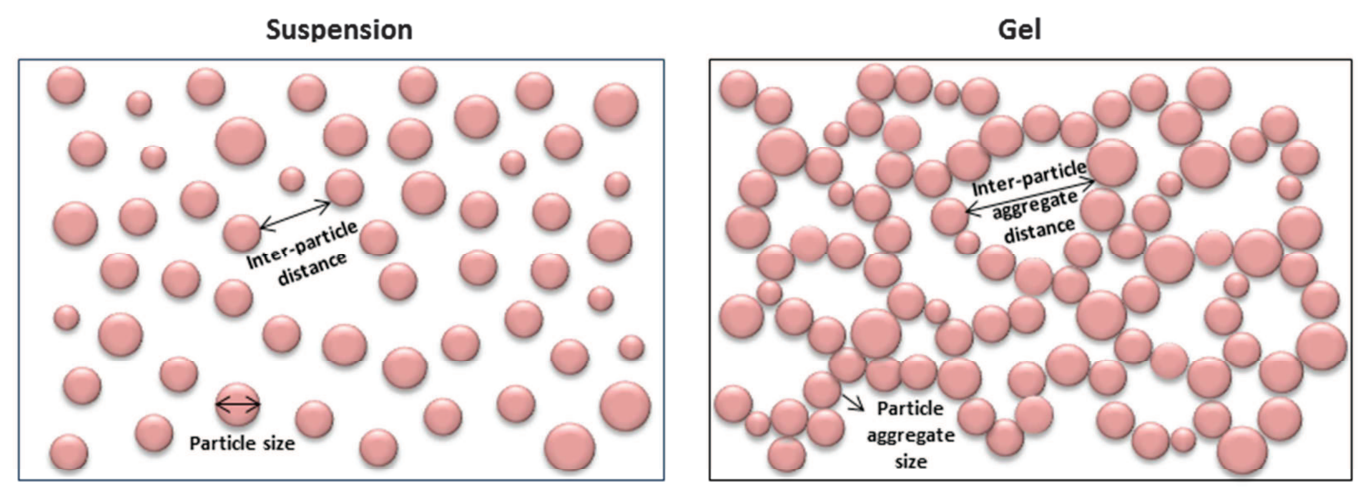


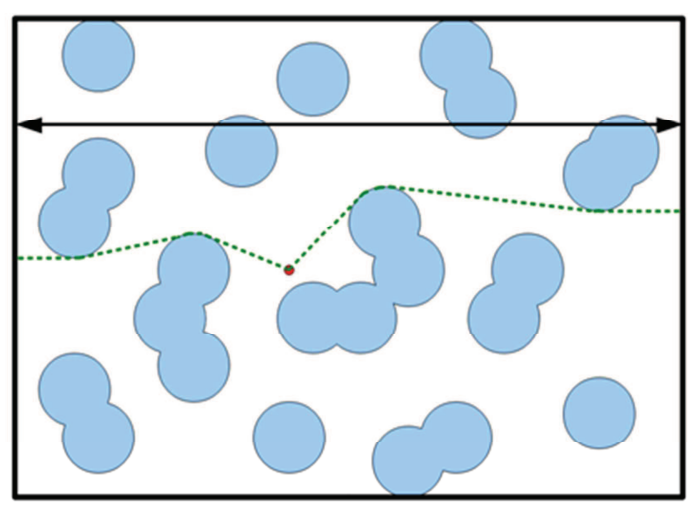



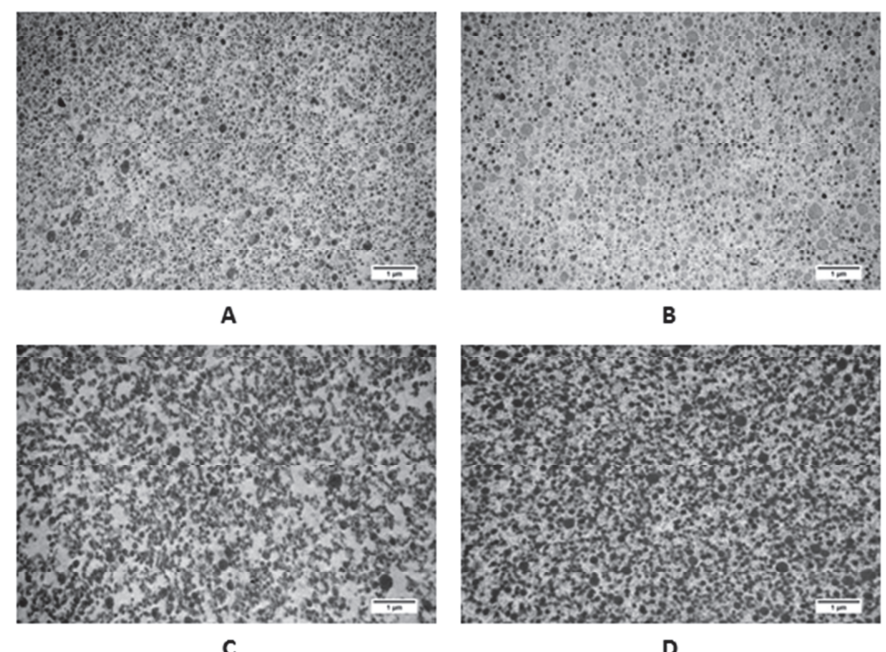

c 

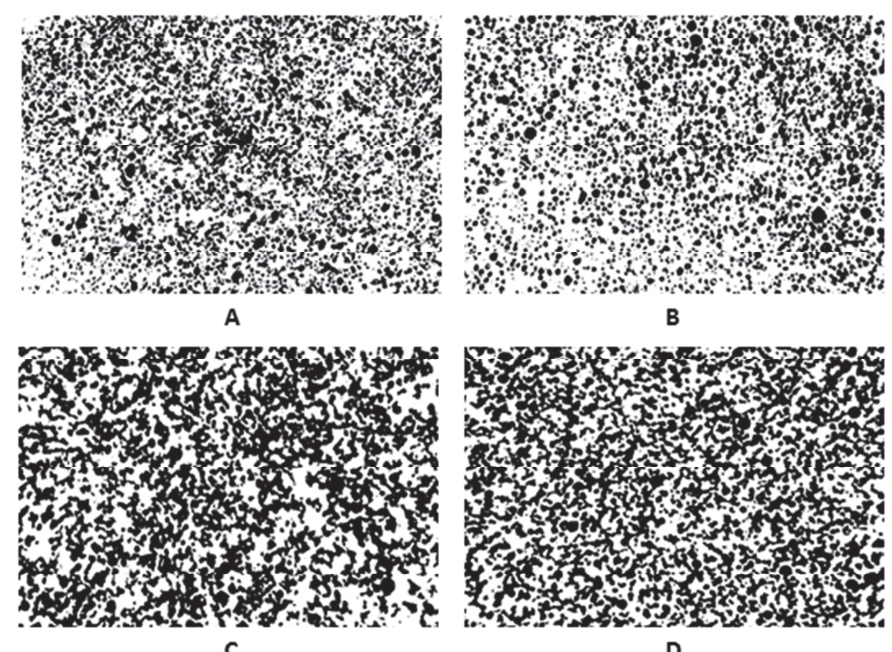

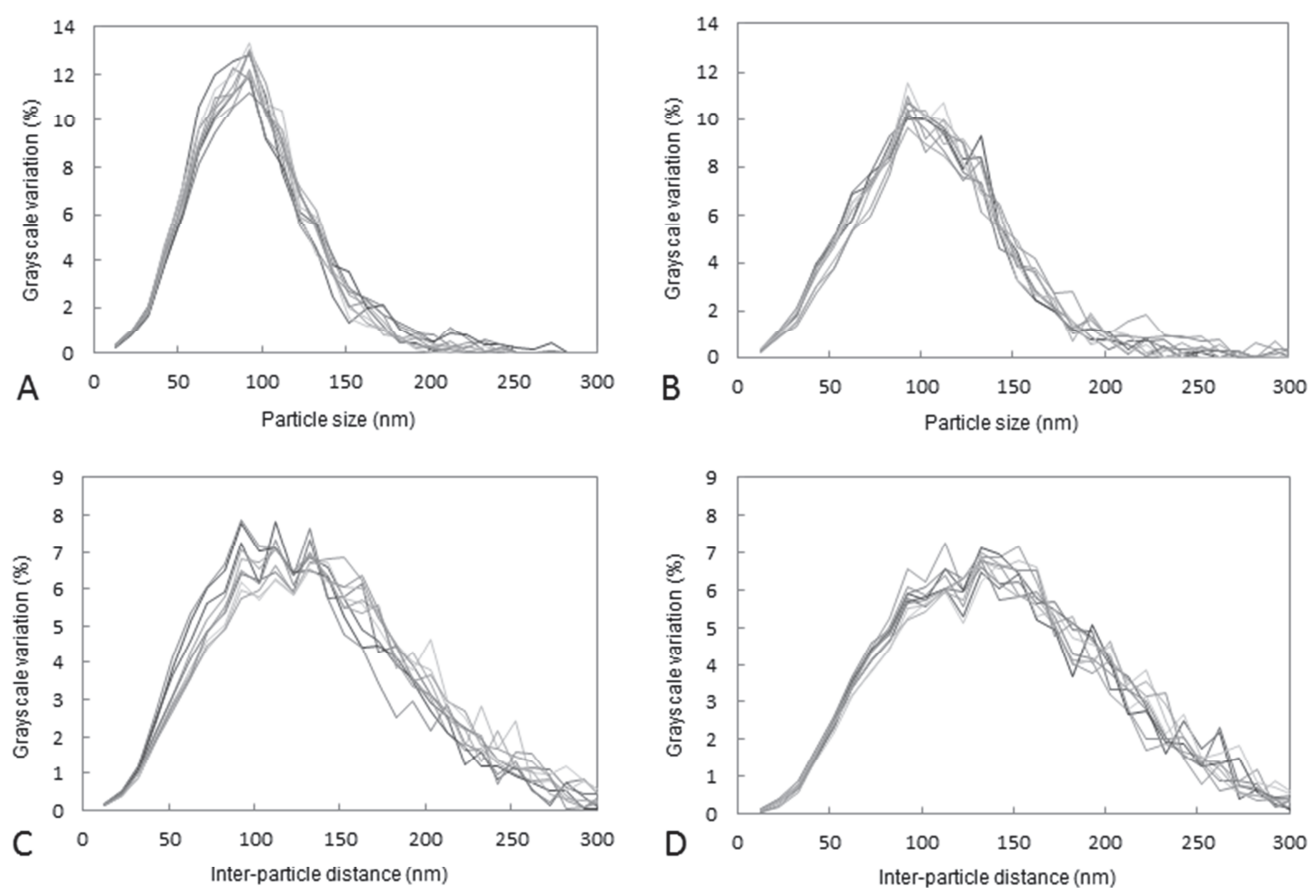

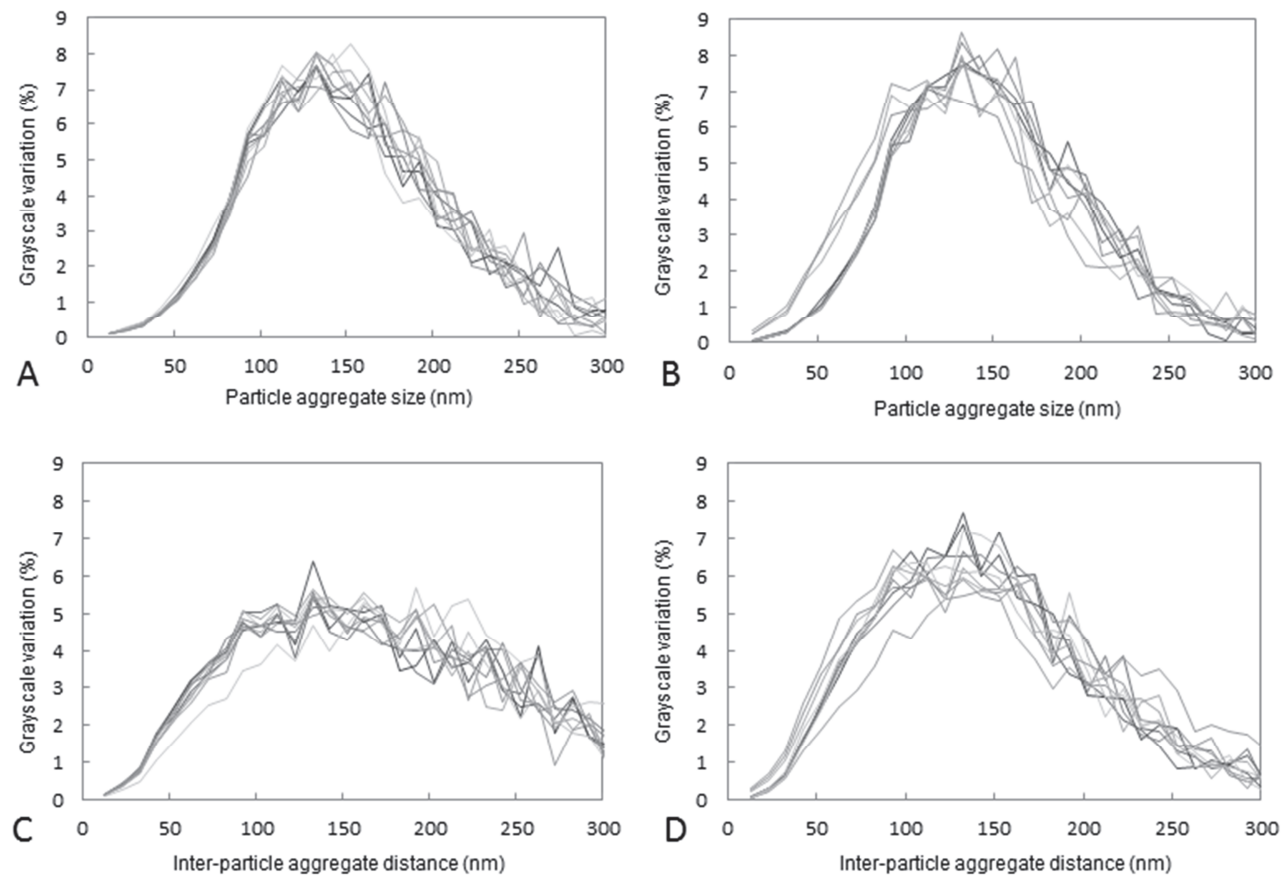


\section{Highlights}

- We developed a method of characterization of the microstructure of dairy systems.

- Microstructural parameters were determined by an automated image analysis method.

- These routine measurements provided discrimination between different dairy systems.

- This method applied to milk gels can be easily transferred to other food systems. 